\title{
JULGAMENTO E TOMADA DE DECISÃO DOS CONTADORES NO PROCESSO DE CONTROLE DO ATIVO IMOBILIZADO
}

\section{JUDGMENT AND DECISION MAKING OF ACCOUNTANTS IN THE ASSET CONTROL PROCESS}

\section{JUICIO Y TOMA DE DECISIONES DE LOS CONTADORES EN EL PROCESO DE CONTROL DE ACTIVOS FIJOS}

Recebido em: 07-11-2019

Avaliado em: 17-06-2020

Reformulado em: 05-08-2020

Aceito para publicação em: 17-08-2020

Publicado em: 21-04-2021

Editor Responsável: Moacir M. Rodrigues Junior

\author{
Angela Maria Haberkamp ${ }^{1}$ \\ Norberto Hoppen ${ }^{2}$ \\ Clóvis Antônio Kronbauer ${ }^{3}$
}

\section{RESUMO}

Este estudo analisou características individuais e pressões institucionais que influenciam o julgamento e a tomada de decisão (JDM) de contadores em empresas que adotam as International Financial Reporting Standards (IFRS) e como o fazem no processo de controle do imobilizado. Como lente teórica foram utilizadas a Teoria da Racionalidade Limitada e a Teoria Institucional. Dados foram coletados junto a 28 contadores de grandes empresas brasileiras. Os resultados revelaram que tanto as características individuais - limitações cognitivas, informacionais e situacionais - quanto as pressões institucionais - coercitivas, normativas e miméticas - influenciam o JDM dos contadores. Baseado na frequência dos elementos analisados, constatou-se que, das características individuais, as limitações cognitivas - excesso de variáveis, uso de classificações prévias - foram as mais importantes, sendo identificadas nas falas de 26 contadores. Dentre as pressões institucionais, a coercitiva - legislação, gestores, auditoria - foi a mais importante (mencionada por todos os contadores). Os resultados evidenciaram, também, que as limitações cognitivas influenciam mais intensamente o JDM nas decisões operacionais, enquanto as pressões coercitivas influenciam mais as decisões relacionadas à gestão do imobilizado. Além disso, quando ocorrem eventos em que limitações individuais e pressões institucionais influenciam o JDM de forma conjunta, as pressões coercitivas são as determinantes.

Palavras-chave: Julgamento e Tomada de Decisão; IFRS; Racionalidade Limitada; Teoria Institucional; Controle de Ativos Fixos.

\footnotetext{
${ }^{1}$ Doutora em Ciências Contábeis pela Universidade do Vale do Rio dos Sinos (UNISINOS); Professora do Centro de Gestão Organizacional, Universidade do Vale do Taquari (UNIVATES); E-mail: angelamh@univates.br

${ }^{2}$ Doutor em Administração pela Universidade de Grenoble-Alpes - França; Pesquisador Voluntário dos Programas de Pós-Graduação em Administração e em Ciências Contábeis da Universidade do Vale do Rio dos Sinos (UNISINOS). Email: norbertohoppen@gmail.com

${ }^{3}$ Doutor em Contabilidad y Auditoria pela Universidade de Sevilla - Espanha; Professor do Programa de Pós-Graduação em Ciências Contábeis da Universidade do Vale do Rio dos Sinos (UNISINOS); E-mail: clovisk@unisinos.br
} 


\section{ABSTRACT}

This study analyzed individual characteristics and institutional pressures that influence the judgment and decision-making (JDM) of accountants in companies that adopt the International Financial Reporting Standards (IFRS) and how they proceed in the asset control process. As theoretical lenses, we adopted the Limited Rationality and Institutional Theories. Data were collected from 28 accountants of large Brazilian companies. Based on the frequency of the elements analyzed, results revealed that both individual characteristics - cognitive, informational, and situational limitations - as well as institutional pressures - coercive, normative, and mimetic - influence the JDM of accountants. Cognitive limitations - excess of variables, use of previous classifications - were the most important individual characteristics, identified in the answers of 26 accountants, and coercive pressure legislation, managers, auditing - was the most important institutional pressure (mentioned by all accountants). The results also showed that cognitive limitations influence JDM more strongly in operational decisions, while coercive pressures influence asset management decisions. Moreover, when events occur in which individual limitations and institutional pressures jointly influence JDM, coercive pressures are the determinants.

Keywords: Judgment and Decision-making; IFRS; Bounded Rationality; Institutional Theory; Asset Control.

\section{RESUMEN}

Este estudio analizó las características individuales y las presiones institucionales que influyen el juicio y la toma de decisiones (JDM) de los contadores en las empresas que adoptan las Normas Internacionales de Información Financiera (NIIF) y cómo lo hacen en el proceso de control de activos. Como lente teórica se utilizaron la teoría de la racionalidad limitada y la institucional. Se recopilaron datos de 28 contadores de empresas brasileñas que adoptaron el NIIF. Basado en la frecuencia de los elementos analizados, los resultados revelaron que tanto las características individuales (limitaciones cognitivas, informativas y situacionales) como las presiones institucionales (coercitivas, normativas y miméticas) influyen en la JDM de los contadores. De las características individuales, las limitaciones cognitivas (exceso de variables, uso de clasificaciones previas) fueron las más importantes (citado por 26 entrevistados), y las presiones institucionales coercitivas (legislación, gerentes, auditoría) fueron las más importantes (citado por todos los entrevistados). Los resultados también mostraron que las limitaciones cognitivas influyen más en JDM en las decisiones operativas, mientras que las presiones coercitivas influyen en las decisiones relacionadas con la gestión de activos fijos. Además, cuando se producen eventos en los que las limitaciones individuales y las presiones institucionales influyen conjuntamente en la JDM, las presiones coercitivas determinan la decisión.

Palabras-clave: Juicio y toma de decisiones; NIIF; Teoría de la racionalidad limitada; Teoría institucional; Control de activos fijos.

\section{INTRODUÇÃO}

O principal objetivo da contabilidade é fornecer informações úteis à tomada de decisão dos stakeholders - os gestores e investidores. No Brasil, esse processo ganhou maior importância em 2010, com a obrigatoriedade de adoção das International Financial Reporting Standards (IFRS) pelas companhias de capital aberto, que possibilitaram a convergência das normas contábeis aos padrões internacionais. Antes da adoção das IFRS predominavam padrões de mensuração baseados nas determinações constantes na legislação fiscal (Freire, Machado, Machado, Souza, \& Oliveira, 2012). No entanto, a mudança de normas não provocou a adoção imediata dos novos padrões IFRS na contabilidade brasileira. Dentre as principais razões estão a novidade do tema, a forma da condução 
da convergência (Caríssimo \& Pinheiro, 2012) e o aumento dos custos relacionados ao controle e levantamento das informações (Nakane \& Peres, 2014).

Dentre as pesquisas relacionadas às alterações introduzidas pelas IFRS no Brasil (Politelo, Kaveski, \& Klann, 2014; Santiago, Cavalcante, \& Paulo, 2015), o controle do ativo imobilizado é objeto de estudos recorrentes, porque esses itens são significativos em relação ao valor total dos ativos da empresa. Em função da necessidade de adequações decorrentes do impairment em seus ativos, as empresas podem apresentar impactos expressivos em seu patrimônio e no resultado. Por exemplo, recentemente, grandes empresas brasileiras realizaram baixas decorrentes de impairment: em 2016 a Petrobrás registrou perdas de quase R \$ 21 bilhões e a Vale de R \$ 5,9 bilhões; em 2017 a Dommo Energia registrou perdas de $\mathrm{R} \$ 650$ milhões e a BR Pharma de $\mathrm{R} \$ 872$ milhões.

Antes das IFRS, a mensuração do imobilizado era fortemente influenciada pela legislação fiscal brasileira. Em relação a isso, as IFRS representam um avanço, pois possibilitam a adoção de critérios que prezem pela qualidade da informação, permitindo que a contabilidade cumpra sua função de gerar informações para a tomada de decisão. A mudança de uma contabilidade baseada em regras para uma baseada em princípios aumentou o grau de julgamento do contador (Ernest and Young \& FIPECAFI, 2010). A própria Estrutura Conceitual da Contabilidade (CFC, 2011, p. 3) define que "em larga extensão, os relatórios contábil-financeiros são baseados em estimativas, julgamentos e modelos e não em descrições ou retratos exatos", evidenciando, assim, a necessidade de julgamento. Esse julgamento é utilizado no controle do imobilizado: registro, mensuração, cálculo da depreciação, teste de impairment e baixa. Para Iudícibus, Martins, Gelbcke e Santos (2018), o controle adequado do patrimônio configura-se como um ponto importante para a apresentação da situação econômicofinanceira das empresas, pois é utilizado como base para cálculo dos indicadores financeiros. Logo, alterações em seu valor podem influenciar os stakeholders (principalmente investidores) em suas decisões de investimentos. Carvalho, Lima e Ferreira (2012) afirmam que, com a convergência, os principais pontos a serem considerados são a mensuração dos seus valores contábeis, da depreciação e o teste impairment.

O contador é o responsável legal pela elaboração e pelo conteúdo das demonstrações contábeis. Porém, a decisão de adotar ou não determinada norma e de como operacionalizá-la é influenciada por diferentes aspectos. Bonner (1999) identificou duas variáveis no processo de JDM utilizado por um contador: o indivíduo e o ambiente. Espera-se que os indivíduos tratem as informações de forma objetiva e sem vieses. Contudo, várias características do contador influenciam seu julgamento (Mala \& Chand, 2015). Identificar e escolher as melhores alternativas faz parte de uma tarefa complexa, o que dificulta a previsão dos possíveis efeitos nas decisões, evidenciando limites da racionalidade (Silva \& Naldis, 2012). Além disso, os pronunciamentos contábeis estabelecem apenas os conceitos que servem para os modelos, estimativas e julgamentos utilizados (CFC, 2011). Por isso, além de ter sido reconhecida no meio acadêmico, também no campo empírico se pode identificar a importância de estudar o JDM dos contadores.

O contexto do problema de pesquisa é motivado pelas alterações ocorridas na contabilidade brasileira. Dentre as alterações mais relevantes estão a primazia da essência sobre a forma, a existência de normas contábeis orientadas por princípios e a necessidade do julgamento por parte dos profissionais de contabilidade (Iudícibus et al., 2018). Destas, a necessidade de julgamentos merece destaque.

A tomada de decisão pode ser compreendida a partir de diversas lentes teóricas: algumas com foco na dimensão individual, outras na dimensão organizacional (Eisenhardt \& Zbaraki, 1992). Conforme Bonome (2009), para os agentes que tomam decisões, existem dois tipos de fatores que supõem limitações: as características da sua mente e os contornos externos ou o ambiente. Para auxiliar na compreensão de como ocorre esse processo, foram utilizadas como lente teórica a Teoria Institucional (DiMaggio \& Powell, 1983) e a Teoria da Racionalidade Limitada (Simon, 1965). Ambas analisam de modo parcial e complementar importantes problemas encontrados nas 
organizações (Zorn, Flanagin, \& Shoham, 2010). Existem poucos estudos empíricos na área contábil que adotam esta abordagem.

Com base no exposto, a questão de pesquisa resultante foi como ocorre o JDM dos contadores no processo de controle do ativo imobilizado? O objetivo do estudo foi analisar quais são e como elementos cognitivos e situacionais individuais e pressões institucionais influenciam o JDM de contadores em empresas que adotaram as IFRS. Os dados foram coletados junto a 28 contadores de empresas do Rio Grande do Sul e São Paulo, responsáveis pelas demonstrações contábeis. Todos os respondentes participam da definição das premissas e práticas contábeis utilizadas na elaboração das demonstrações financeiras disponibilizadas aos stakeholders. Foi utilizado um questionário semiestruturado para coletar os dados, os quais foram submetidos a uma análise categórica.

Na sequência, o artigo está estruturado nas seções de fundamentação teórica, metodologia, análise e discussão dos resultados e considerações finais.

\section{FUNDAMENTAÇÃO TEÓRICA}

O estudo do JDM dos contadores fundamentou-se na Teoria da Racionalidade Limitada, uma das mais influentes nos estudos sobre tomada de decisão (Lee, Keil, \& Wong, 2018), e na Teoria Institucional (DiMaggio \& Powell, 1983), que é utilizada regularmente para analisar as escolhas contábeis (Dufour, Teller, \& Luu, 2015).

\subsection{0 julgamento e a tomada de decisão}

O termo julgamento representa a formação de uma ideia, opinião ou estimativa sobre um fenômeno. O termo decisão refere-se à definição de um curso de ação em relação a esse fenômeno (Bonner, 1999). Para Simon (1955), o processo de JDM segue três etapas sucessivas: a identificação do problema, a escolha e a implementação da alternativa escolhida - a decisão. De maneira geral, o processo é complexo, pois cada etapa é composta por uma série de processos em níveis menores. As etapas são independentes e complexas, mas inter-relacionadas (Tversky \& Kahneman, 1974).

Dentre os aspectos cognitivos relacionados à execução da contabilidade, está a necessidade de JDM. Para Trotman, Tan e Ang (2011), os auditores, preparadores das demonstrações contábeis, contadores, analistas, investidores e gestores são os responsáveis pela tomada de decisão em contabilidade. Qi (2014) refere-se ao julgamento na área contábil como um processo em que os contadores usam seus conhecimentos profissionais para avaliar e selecionar os resultados do trabalho contábil diário, de acordo com a operação da empresa, as normas contábeis e o sistema contábil.

\subsection{Teoria da racionalidade limitada}

O conceito de racionalidade limitada foi apresentado por Simon (1955), que o contrapôs à visão clássica de que os gestores tomam decisões ótimas, com objetivo de maximizar o lucro. Para o autor, somente os fatores que estão estreitamente ligados casual e temporalmente com a decisão são levados em consideração. Dessa forma, o indivíduo toma decisões que atendam a padrões mínimos, satisfatórios. Na racionalidade limitada não se supõe que o decisor desenhe todas as consequências lógica e matematicamente válidas, porque ele não dispõe de todas as informações que são relevantes para determinar suas escolhas ótimas (Ross, 2014). Como as soluções ótimas estão além da capacidade de processamento humano, os decisores procuram encontrar alternativas para identificar soluções nas quais o ótimo é substituído pelo satisfatório (satisficing) (Simon, 1965).

As limitações advindas da racionalidade limitada, segundo Simon (1965) e literatura posterior (Davis, Olson, \& Gama, 1987), podem ser subdivididas em cognitivas, situacionais e informacionais. Aspectos cognitivos mostram que o tomador de decisão é limitado por aspectos individuais, relacionados à sua capacidade mental, hábitos e conhecimento em relação ao seu trabalho (Davis, Olson, \& Gama, 1987). Uma das estratégias que pode ser adotada é utilizar facilitadores de decisão (Bonome, 2009). 
Já as limitações situacionais estão relacionadas a aspectos do ambiente no qual são tomadas as decisões, sendo caracterizadas pelo tempo limitado para a tomada de decisão (Sbicca, 2014) e pelo envolvimento do decisor em múltiplas tarefas. As limitações informacionais decorrem dos altos custos de busca da informação (Sbicca, 2014; KPMG, 2011) e da falta ou indisponibilidade das informações (Sbicca, 2014; Simon, 1965).

Embora os elementos da racionalidade limitada já tenham sido utilizados na área da contabilidade, ainda são incipientes no que se refere a estudos de adoção das IFRS e da tomada de decisão relacionada ao controle do imobilizado. Laitinen e Laitinen (2015) concluíram que elementos da racionalidade limitada influenciam na auditoria e, mesmo que o auditor não seja capaz de identificar todas as falhas, o que poderia ser caracterizado como um resultado ótimo, seu desempenho é satisfatório. Chand, Patel e Patel (2010) identificaram que a interpretação e a aplicação das IFRS são afetadas pela complexidade da norma contábil e pela familiaridade do contador com ela. Binswanger (2012) identificou que os modelos de definição padrão do ciclo de vida dos ativos englobam decisões econômicas complexas, nas quais a racionalidade limitada é uma preocupação relevante.

De forma geral, os modelos de racionalidade limitada sugerem que a tomada de decisão sob incerteza pode ser mais fácil quando alguma informação é ignorada, especialmente se essa informação é desconhecida para o decisor (Smith, 2005). Por isso, entende-se que racionalidade limitada tem potencial para trazer uma nova perspectiva sobre os estudos em contabilidade. Com base nos conceitos apresentados na seção 2.2 , foi definida a primeira proposição desta pesquisa:

P1: Os contadores encontram dificuldades em aplicar as IFRS integralmente, em função de limitações cognitivas, situacionais e informacionais.

\subsection{Teoria institucional}

A abordagem institucional preconiza que as organizações são levadas a incorporar práticas e procedimentos que predominam no seu ambiente, levando a mudanças (Meyer \& Rowan, 1977; North, 1992). Essas mudanças, segundo DiMaggio e Powell (1983), ocorrem porque forças ou pressões institucionais são exercidas e provocam o isomorfismo.

A contabilidade, sob a ótica dessa teoria, é uma rotina institucionalizada que forma entendimentos em relação às atividades, seguindo normas e procedimentos específicos que permitem a tomada de decisões (Scapens, 1994). Para Dias Filho e Machado (2012), em algumas situações, ao invés de a contabilidade ser utilizada para fornecer subsídios para tomada de decisões, ela acaba se tornando um instrumento de legitimação das decisões adotadas. Por isso, no contexto das IFRS, a institucionalização pode ser vista como um processo social, no qual contadores abrem mão das normas contábeis nacionais em favor da convergência com normas contábeis internacionais (Rodrigues \& Craig, 2007).

As forças institucionais são identificadas como pressões isomórficas por Dimaggio e Powell (1983). Para os autores, há três mecanismos de mudança isomórfica institucional: o coercitivo, o mimético e o normativo. O isomorfismo coercitivo resulta de pressões formais e informais, que podem ser sentidas como coerção, persuasão, convites para se unirem em conluio, ou como uma resposta direta a ordens governamentais (DiMaggio \& Powell, 1983). Scott (2008), por sua vez, associa o isomorfismo coercitivo à regulação, envolvendo a capacidade de estabelecer regras, fiscalizar a conformidade e, se necessário, manipular sanções, recompensas ou punições, em uma tentativa de influenciar o comportamento futuro.

Estudos mostram que na contabilidade, dentre os grupos de pressão do isomorfismo coercitivo, estão aqueles com capacidade de promulgar leis, normas e regulamentos (Touron, 2005), como as entidades regulamentadoras da contabilidade nacional, a bolsa de valores, os poderes executivo e legislativo (Doadrio, Alvarado, \& Carreira, 2015), os mercados financeiros (Albu, Albu, 
Bunes, \& Cala, 2011) e as partes interessadas principais, como fornecedores de capital (investidores, bancos e credores) ou autoridades fiscais (Zarzeski, 1996). Parboteeah, Cullen, Victor e Sakano (2005) constataram que organizações profissionais contábeis também têm efeitos reguladores coercitivos sobre a profissão (e os profissionais).

O isomorfismo normativo está associado a profissionais que executam atividades similares em diferentes organizações, tratando os problemas de forma similar. As profissões estão sujeitas às mesmas pressões que as organizações, pois, enquanto os profissionais de uma organização devem diferenciar-se uns dos outros, eles exibem muita similaridade com suas contrapartes em outras organizações (DiMaggio \& Powell, 1983). A profissão dos contadores é controlada e institucionalizada por regras sociais de licenciamento, certificação e escolaridade (Parboteeah et al., 2005). No Brasil, para que possa exercer a profissão, o contador deve estar vinculado ao conselho de classe e seguir suas recomendações. O não cumprimento das resoluções e normas estabelecidas pode gerar punições, que variam de advertências à cassação do registro profissional (Brasil, 1946).

Normas e valores da profissão contábil também influenciam práticas contábeis nos EUA e Japão (Parboteeah et al., 2005). Pressões internacionais da profissão contábil influenciaram o Egito na adoção das IFRS (Hassan, 2008). Os auditores possuem papel decisivo no surgimento de práticas contábeis (Touron, 2005). Dufour, Teller e Luu (2015) identificaram diferenças no isomorfismo normativo entre os países, pois os níveis de formação dos membros da profissão contábil não são os mesmos em todos os lugares.

O isomorfismo mimético resulta das incertezas de mercado, da ambiguidade organizacional e das desvantagens perante a concorrência, levando muitas organizações a imitar comportamentos adotados em outras. Os comportamentos podem ser difundidos involuntária e indiretamente por meio da transferência ou rotatividade de funcionários, ou explicitamente por organizações como empresas de consultoria (DiMaggio \& Powell, 1983). O isomorfismo mimético emerge na fase formativa de um campo ou durante uma fase de reformulação provocada por uma grande inovação (Tuttle \& Dillard, 2007), quando os adotantes iniciais constituem um modelo para a mudança (Zucker, 1987).

$\mathrm{O}$ isomorfismo mimético foi identificado em diferentes aspectos relacionados à prática da contabilidade. Callado e Pinho (2015) o identificaram na gestão de custos de micro e pequenas empresas; Dias, Lima Filho, Pinheiro, Silva e Moreira (2014) na evidenciação das informações socioambientais; e Rezende, Guerreiro, e Dalmacio (2012) pela presença das empresas de auditoria e consultoria. Assim, com base nos conceitos da Teoria Institucional e nos estudos anteriormente apresentados, foi estruturada a proposição P2a desta pesquisa:

P2a: O JDM dos contadores é influenciado por pressões isomórficas coercitivas, miméticas e normativas no processo de controle do imobilizado.

As pressões institucionais podem surgir e ser percebidas de forma e com intensidade diferentes, em função das ações que elas desencadeiam e porque se encontram em diferentes estágios de institucionalização (Zucker, 1987). Já para Scott (2008), os elementos que caracterizam as pressões isomórficas (e.g. procedimentos de trabalho) são importantes. Segundo o autor, por vezes alguns elementos são mais importantes que outros. Alguns valores e normas são aplicáveis a todos os membros da coletividade, enquanto outros só se aplicam a alguns membros e em graus variados. No processo de adoção das IFRS em nível global, as pressões isomórficas se manifestam de diferentes formas. Com base nos três tipos de isomorfismo e, principalmente, considerando que estudos anteriores (Zucker, 1987; Scott, 2008) mostraram que a pressão exercida pelas diferentes formas de isomorfismo ocorre de forma desigual, foi definida a proposição P2b desta pesquisa:

P2b: O JDM dos contadores é mais influenciado pela pressão coercitiva do que pelas pressões miméticas e normativas no processo de controle do imobilizado. 
O contexto institucional da Contabilidade no Brasil é fortemente normatizado regulamentação da profissão e do exercício profissional (Brasil, 1946; CFC, 2019a), regulamentação dos padrões de elaboração e divulgação do relatório contábil financeiro (CFC, 2011), legislação fiscal, legislação internacional (Ernest\&Young \& FIPECAFI, 2010). Com o propósito de integrar, analiticamente, o contexto normatizado e estudos empíricos sobre a influência das pressões institucionais na adoção de normas contábeis que adotaram a Teoria Institucional (Carneiro, Rodrigues, \& Craig, 2017; Hassan, 2008) com a Teoria da Racionalidade Limitada, (Bonoma, 2009; Sbicca, 2014; Laitinen \& Laitinen, 2015), foi formulada a proposição P3 desta pesquisa:

P3: O JDM dos contadores é mais influenciado pelas pressões institucionais do que pelas limitações individuais no processo de controle do ativo imobilizado.

\section{PROCEDIMENTOS METODOLÓGICOS}

Para compreender o processo de adoção das IFRS em empresas brasileiras, optou-se por estudar o fenômeno sob a ótica de um dos principais agentes envolvidos no processo: o contador. Considerando que a adoção das IFRS foi exigida inicialmente nas companhias abertas e naquelas empresas que têm obrigação pública de prestação de contas (Brasil, 2007), que parece estar relacionada ao porte das empresas (Silva, Silva, \& Laurencel, 2016), buscou-se aplicar a pesquisa a contadores de grandes organizações, com ativos imobilizados de valor monetário relevante para a consecução das suas atividades fim, como indústrias e prestadoras de serviço (transportes, saúde e educação). Buscou-se também, diversificar os ramos de atividade (indústria alimentícia, automotiva, vestuário, serviços de transporte, educacionais e de saúde) porque, de acordo com as pesquisas de Andrade, Fontana e Macagnan (2013) e Politelo, Kaveski e Klann (2014), estes apresentam variação do grau de aderência às normas IFRS.

Foram contatados contadores de 58 organizações (83 ligações telefônicas e 48 e-mails), com o objetivo de agendar entrevistas. Do total de contatados, 33 concordaram em participar da pesquisa. Apesar de a análise prévia indicar que a empresa atendia os requisitos das IFRS, no momento da realização da entrevista, constatou-se que cinco empresas não o faziam, sendo excluídas da amostra. Os 28 entrevistados são de 17 empresas do ramo industrial e 11 de prestadoras de serviços, localizadas nos estados do Rio Grande do Sul (25) e São Paulo (3). O seu faturamento anual oscila entre R \$ 63 milhões e R \$ 10,4 bilhões de reais, caracterizando uma amostra composta por grandes empresas. Dos 28 entrevistados, 20 são contadores, 6 controllers e 2 auxiliares de contabilidade. Destes, 15 são do gênero feminino e 13 do masculino. Todos são graduados em Ciências Contábeis, sendo que 15 realizaram cursos de especialização e oito de mestrado. A idade média é de 41 anos (entre 28 e 55). As entrevistas foram realizadas entre setembro de 2016 e março de 2017.

$O$ roteiro de entrevistas compreende 13 questões e leva em consideração os processos e etapas envolvidos no controle do imobilizado (CFC, 2017a; CFC, 2017b), (ver detalhes no Apêndice A). As questões foram formuladas com o objetivo de identificar possíveis limitações individuais e situacionais, e pressões que influenciam o JDM de contadores, conforme sugere a literatura prévia sobre o tema.

Os requisitos de validade recomendados por Kirk e Miller (1986) foram atendidos. Envolveram validade teórica (exploração do campo com análise das normas e visitas a empresas que adotaram as IFRS, detalhamento dos fundamentos das questões) e aparente (análise das duas primeiras versões do instrumento por três especialistas e um profissional, sendo adotada a terceira versão). Já os requisitos de confiabilidade incluíram preceitos de Lincoln e Guba (1985). Envolveram credibilidade (envolvimento prolongado de um dos pesquisadores no campo, discussão das questões entre pesquisadores, comparação das respostas com demonstrações publicadas pelas empresas, validação dos resultados por sete entrevistados), transferibilidade (gravação e transcrição integral das entrevistas, descrição e exemplificação dos códigos de análise), confiabilidade (confronto entre 
transcrições e gravações das entrevistas, leitura e releitura dos códigos e das codificações realizadas, análise dos dados em duas rodadas, acompanhada de discussão entre os pesquisadores para harmonizar eventuais discrepâncias) e confirmabilidade (gerenciamento da base de dados contendo entrevistas gravadas e transcritas, documentos, notas do pesquisador, contatos dos entrevistados). Os procedimentos adotados estão detalhados a seguir.

A coleta de dados ocorreu em duas etapas. Inicialmente, para compreender o cenário do processo de controle do imobilizado sob o ponto de vista dos contadores, foi realizada uma análise das normas relacionadas à adoção das IFRS no Brasil (CFC, 2011; CFC, 2017a; CFC 2017b; Brasil, 2007) e também foram realizadas visitas e entrevistas com contadores de empresas que adotaram as IFRS. Estas entrevistas não fizeram parte da amostra. Em seguida foram realizadas as 28 entrevistas, que foram gravadas e transcritas. A transcrição foi confrontada com o áudio e as notas de campo foram utilizadas para inserir informações relacionadas ao contexto e à percepção dos pesquisadores. Com o propósito de aumentar a confiabilidade do processo, as entrevistas foram codificadas e analisadas com o auxílio de Atlas. TI, um dos softwares de análise qualitativa mais utilizados (Paulus, Woods, Atkins, \& Macklin, 2017).

As questões abertas do roteiro permitiram, ao mesmo tempo, preservar a comparabilidade das respostas e fazer adaptações, de acordo com os conhecimentos e interesses de cada entrevistado. $\mathrm{O}$ primeiro bloco continha perguntas relacionadas às etapas do processo de controle do imobilizado: reconhecimento, mensuração, cálculo da depreciação, teste de impairment e baixa. Essa parte do questionário teve como objetivo identificar as limitações individuais e as pressões institucionais no JDM dos contadores, bem como, compreender como esses elementos influenciam, de forma conjunta, o JDM. As perguntas do segundo bloco tinham como objetivo caracterizar o perfil do respondente. As entrevistas totalizaram 15 horas e 46 minutos de gravação (média de 31 minutos por entrevista).

Os dados foram analisados com base nas etapas de codificação propostas por Saldaña (2009). Conforme as entrevistas foram sendo realizadas, eram também transcritas. As categorias, a priori oriundas da literatura - limitações cognitivas, situacionais e informacionais (Teoria da Racionalidade Limitada), e pressões coercitivas, miméticas e normativas (Teoria Institucional) - representam constructos mais abrangentes. Por isso, foram criadas subcategorias para criar elementos de análise mais operacionais e identificar as unidades de registro, a partir da literatura revisada (em especial Simon, 1965; Davis, Olson, \& Gama, 1983; Bonoma, 2009; Sbicca, 2014 para a primeira teoria, e DiMaggio \& Powell, 1983; Freitas \& Guimarães, 2007; Touron, 2005; Zucker, 1987; Parboteeah et al., 2005 para a segunda) e, a partir da análise das normas IFRS. Para manter a uniformidade da codificação (Saldaña, 2009), cada categoria foi descrita com suas subcategorias e foi exemplificada. Ao iniciar a codificação de uma nova entrevista, o conceito do código era revisto e todas as codificações anteriores eram lidas. Após a primeira rodada de codificações, ocorreu a reanálise dos códigos, com a junção de subcategorias (por similaridade e relevância). Com isso, a quantidade de categorias foi mantida (porque estas foram originadas na literatura), porém, as subcategorias foram reduzidas de 26 para 17.

Para identificar como os elementos da Teoria da Racionalidade Limitada e da Teoria Institucional influenciam o JDM dos contadores de forma conjunta, foram identificadas as codificações simultâneas propostas por Saldaña (2009) e adotada a Técnica de Incidentes Críticos, de Flanagan (1973). Foram considerados incidentes críticos, aquelas situações em que foi possível identificar a presença de elementos da racionalidade limitada e de pressões institucionais no JDM dos contadores, em um único incidente.

Uma síntese dos resultados foi enviada por e-mail aos contadores entrevistados, solicitando que manifestassem sua impressão em relação aos resultados obtidos. Dos 28 entrevistados, sete atestaram a credibilidade dos resultados da pesquisa, como exemplificado por E21: "Entendo que os resultados são muito pertinentes ao assunto". 


\section{ANÁLISE E DISCUSSÕES DOS RESULTADOS}

Nesta seção são analisados a racionalidade limitada e as pressões isomórficas institucionais que influenciam o JDM dos contadores no controle do imobilizado. Também são analisados incidentes críticos para identificar como elementos de ambas as teorias influenciam o JDM dos contadores de forma conjunta.

\subsection{A influência das limitações individuais}

Estudos baseados na racionalidade limitada avaliam, majoritariamente, se há a presença do critério satisfatório em detrimento da decisão ótima, sem se aprofundar nos elementos que contribuem para essa decisão não ótima. Por isso, buscou-se identificar os elementos que permitem compreender de que forma a racionalidade limitada se manifesta no JDM dos contadores no processo de controle do imobilizado - P1: Os contadores encontram dificuldades em aplicar as IFRS integralmente, em função de limitações cognitivas, situacionais e informacionais -. Os resultados encontrados (ver Tabela 1) confirmam a proposição, uma vez que as três limitações foram identificadas no JDM dos contadores.

Tabela 1 - A influência das limitações individuais

\begin{tabular}{|c|c|c|}
\hline Categorias & Definições & Principais Resultados \\
\hline \multirow{2}{*}{$\begin{array}{l}\text { Limitações } \\
\text { Cognitivas }\end{array}$} & $\begin{array}{l}\text { - O decisor utiliza facilitadores } \\
\text { de decisão (Bonome, 2009; } \\
\text { KPMG, 2011) }\end{array}$ & $\begin{array}{l}\text { - Critérios fiscais (E03: "Para definir os critérios a gente usa a } \\
\text { legislação fiscal"). } \\
\text { - Classificações prévias (E26: "O gestor do setor, da área, } \\
\text { digamos assim, analisa e então eles fazem a primeira } \\
\text { avaliação deles do que eles entendem, se vai ser imobilizado } \\
\text { ou não"). }\end{array}$ \\
\hline & $\begin{array}{l}\text { - O decisor é limitado por sua } \\
\text { capacidade mental, seus } \\
\text { hábitos, reflexos e pelo } \\
\text { conhecimento em relação ao } \\
\text { seu trabalho (Davis, Olson, \& } \\
\text { Gama,1987) }\end{array}$ & $\begin{array}{l}\text { - Excesso de variáveis (E09: "Para a pessoa da controladoria, } \\
\text { ou para mim, conhecer tudo isso é um pouco mais } \\
\text { complicado"). }\end{array}$ \\
\hline $\begin{array}{l}\text { Limitações } \\
\text { Situacionais }\end{array}$ & $\begin{array}{l}\text { - O tempo é limitado para a } \\
\text { tomada de decisão (KPMG, } \\
\text { 2011; Sbicca, 2014) }\end{array}$ & $\begin{array}{l}\text { - Falta de tempo (E08: “Ainda não teve tempo para separar isso } \\
\text { tudo do jeito que deveria ser, se trabalha e arruma isso aos } \\
\text { poucos. Porque tem muito cálculo muita coisa para ser feita, } \\
\text { e nem sempre dá tempo de fazer tudo"). }\end{array}$ \\
\hline \multirow{2}{*}{$\begin{array}{l}\text { Limitações } \\
\text { Informacionais }\end{array}$} & $\begin{array}{l}\text { - Os custos de busca da } \\
\text { informação são elevados } \\
\text { (Sbicca, 2014; KPMG, 2011) }\end{array}$ & $\begin{array}{l}\text { - Custo benefício de obter a informação (E07: “... a carroceria } \\
\text { também não é tão relevante em relação ao caminhão porque } \\
\text { ela não custa muito caro”). }\end{array}$ \\
\hline & $\begin{array}{l}\text { - As informações são } \\
\text { incompletas e não disponíveis } \\
\text { (Sbicca, 2014; Simon, 1965) }\end{array}$ & $\begin{array}{l}\text { - Informação indisponível (E14: “são muitas plantas, são } \\
\text { muitas máquinas, muita coisa antiga"). }\end{array}$ \\
\hline
\end{tabular}

Fonte: elaborado pelos autores.

Dentre as limitações cognitivas está o uso de facilitadores de decisão (critérios fiscais e préclassificações). Considerando que a maior parte dos entrevistados já desempenhava atividades profissionais antes da vigência das IFRS, há indícios de que a manutenção das taxas fiscais representa a sobrevivência de práticas que já vinham sendo utilizadas, o que já havia sido identificado por Messier, Quick e Vandervelde (2014) no julgamento de auditores. O uso de facilitadores de decisão pode tanto prejudicar, quanto beneficiar o JDM. Prejudicar, se o contador incluir um item no imobilizado de forma equivocada, decorrente da pré-classificação realizada. Por outro lado, quando foi indicada a classificação correta, seu uso é benéfico, pois agiliza a decisão do contador. Nesse sentido, o uso dos facilitadores de decisão pode ser visto como uma estratégia que contribui para que o contador possa "dar conta" de todas as demandas da contabilidade. 
A disponibilidade da informação não depende apenas do contador, mas de toda a organização, pois as IFRS demandam, além de informações contábeis, aquelas relacionadas à gestão e às operações. Os contadores evidenciaram que a necessidade de interação com outras áreas é intensa. Por isso, é desejado que todos alterem hábitos e rotinas, implementando controles que não eram necessários antes das IFRS. A interação com outras áreas possibilita a geração de informações mais qualificadas e condizentes com a realidade. Por isso, cabe uma reflexão em relação aos contadores que não manifestaram limitações informacionais, já que estes representam quase metade dos entrevistados. Uma possibilidade é que esses contadores tenham a sua disposição todas as informações de que necessitam. Nesse caso, a limitação é de fato inexistente. Ou então, eles consideram as informações que possuem suficientes para seu JDM, caracterizando o critério satisfatório, que prevalece quando não perdemos tempo tentando obter um máximo, que não irá fazer diferença (Sbicca, 2014). Esse critério, característico da Racionalidade Limitada, pode estar vinculado com a própria orientação da Estrutura Conceitual da Contabilidade (CFC, 2011). A referida norma define que dentre as características qualitativas fundamentais da contabilidade está a relevância, segundo a qual, informação contábil deve ser "capaz de fazer diferença nas decisões que possam ser tomadas pelos usuários." (CFC, 2011, p. 15). Dessa forma, o contador, ao considerar que a informação gerada atende o requisito de relevância, pode estar sendo encorajado pela própria legislação a buscar apenas a informação satisfatória.

A limitação situacional (tempo disponível) também foi identificada, porém, é pouco presente. Este resultado difere de anteriores (Delgado \& Shealy, 2018; Franco, 2009). A pouca influência da limitação de tempo verificada pode estar relacionada com o período em que a pesquisa foi realizada (sete anos após a adoção das IFRS). Ou seja, houve tempo para que processos fossem revisados e os ajustes mais relevantes fossem realizados.

Analisando as limitações de forma conjunta, há indicativos de que existe uma relação entre elas. Os contadores fazem uso relativamente frequente dos facilitadores de decisão, otimizando o tempo necessário para suas decisões, o que pode contribuir para que a limitação de tempo não seja percebida com intensidade. Há ainda o fato de que parte dos contadores não vê vantagens na adoção das IFRS; logo, a realização das tarefas decorrentes da norma tende a não ser prioridade. É possível que a não realização dessas tarefas não seja considerada um problema. Consequentemente, a limitação de tempo ou informacional é menos percebida.

Constata-se que limitações individuais dos contadores no JDM são inerentes à contabilidade, devido a sua complexidade e ao grande número de tarefas envolvidas. Porém, ao mesmo tempo que essas limitações viabilizam operacionalmente o controle do imobilizado, atendendo a característica de relevância exigida pelas IFRS, parece que a internalização do que de fato a norma representa - a aplicação efetiva da essência sobre a forma - ainda não ocorreu. Talvez o maior desafio dos contadores seja o de direcionar seu JDM no sentido de não atender apenas o mínimo exigido pelas IFRS, dentro dos critérios de relevância estabelecidos, mas disponibilizar informações contábeis que melhor representem a realidade da organização. Parece que o equilíbrio entre essas duas perspectivas ainda não foi alcançado.

\subsection{A influência das pressões institucionais}

A discussão dos elementos institucionais que influenciam o JDM dos contadores está fundamentada na Teoria Institucional, na qual pressões institucionais coercitivas, miméticas e normativas fazem com que as organizações se tornem similares no que diz respeito à sua estrutura e principais práticas (DiMaggio \& Powell, 1983). O isomorfismo na adoção das IFRS e na contabilidade foi identificado nos estudos de Doadrio et al. (2015), Barbu e Piot (2012), Parboteeah et al. (2005), Callado e Pinho (2015) e Dias et al. (2014), entre outros. Disso resultou a proposição de pesquisa P2a: O JDM dos contadores é influenciado por pressões isomórficas coercitivas, miméticas e normativas no processo de controle do imobilizado. Os resultados obtidos e detalhados na Tabela 2 a confirmam. 
Em termos gerais, o controle do imobilizado ocorre de forma similar nas organizações estudadas, evidenciando o isomorfismo. Há práticas comuns em todo processo (registro, mensuração, cálculo da depreciação, teste de impairment e baixa). Baseado nas respostas dos entrevistados, os resultados indicam a forte influência das pressões institucionais no JDM dos contadores, com destaque para as coercitivas (443 de um total de 552 citações); as normativas e miméticas estão menos presentes (80 e 29 , respectivamente). Dentre as coercitivas, destaca-se a legislação, citada por todos os contadores de forma recorrente (221 citações). Esse resultado confirma a proposição $P 2 b: O J D M$ dos contadores é mais influenciado pela pressão coercitiva do que pelas pressões miméticas e normativas no processo de controle do imobilizado.

Tabela 2 - A influência das pressões institucionais

\begin{tabular}{|c|c|c|}
\hline Pressões & Definições & $\begin{array}{l}\text { Principais Resultados } \\
\end{array}$ \\
\hline $\begin{array}{l}\text { Pressões } \\
\text { coercitivas }\end{array}$ & $\begin{array}{l}\text { - Resultam tanto de pressões formais } \\
\text { quanto de pressões informais exercidas } \\
\text { sobre as organizações (DiMaggio \& } \\
\text { Powell, 1983). } \\
\text { Exercidas por: } \\
\text { - aqueles com capacidade de promulgar as } \\
\text { leis, normas e regulamentos (Touron, } \\
\text { 2005; Freitas \& Guimarães, 2007), } \\
\text { - entidades regulamentadoras (Doadrio et } \\
\text { al., 2015); } \\
\text { - mercados financeiros (Albu et al., 2011); } \\
\text { - partes interessadas (Zarzeski, 1996). }\end{array}$ & $\begin{array}{l}\text { - Legislação (E10: "se segue a regra de legislação"; E03: } \\
\text { "dentro da fundamentação dos CPCs"). } \\
\text { - Gestores (E15: “é justificado, enviado para a diretoria, } \\
\text { aprovado ou não aprovado" } \\
\text { - Fornecedores de capital (E17: "é validado pela nossa } \\
\text { diretoria, depois, enfim, pelos nossos acionistas"). } \\
\text { - Grupo empresarial (E09: “a gente segue aquilo que está } \\
\text { ali na nossa norma"). } \\
\text { - Auditoria (E19: “a Ernst [\& Young] ressalvou nosso } \\
\text { balanço por causa disso"). } \\
\text { - Entidades regulamentadoras (E26: "nós somos } \\
\text { auditados pela ANS [Agência Nacional de Saúde } \\
\text { Complementar]. Conversando com quem conhece o } \\
\text { processo produtivo e fazendo uma pré-auditoria, não } \\
\text { fizemos mudanças significativas por causa das IFRS”). }\end{array}$ \\
\hline $\begin{array}{c}\text { Pressões } \\
\text { normativas }\end{array}$ & $\begin{array}{l}\text { - Associadas a profissionais que executam } \\
\text { atividades similares em diferentes } \\
\text { organizações, tratando os problemas de } \\
\text { forma similar. (DiMaggio \& Powell, } \\
\text { 1983). } \\
\text { Exercidas por: } \\
\text { - normas e valores da profissão contábil } \\
\text { (Parboteeah et al., 2005; (Hassan, 2008); } \\
\text { - associações profissionais (Doadrio et al., } \\
\text { 2015); } \\
\text { - auditores (Touron, 2005). }\end{array}$ & $\begin{array}{l}\text { - Auditoria (E01: “teve a participação da Delloite com } \\
\text { uma equipe de engenheiros e auditores, que juntos } \\
\text { fizeram o laudo e a gente fez o trabalho conjunto"). } \\
\text { - Professores (E17: “os professores, eles têm a } \\
\text { interpretação da norma e eles vão passar a intepretação } \\
\text { deles né?”). } \\
\text { - Formação (E11: “ a graduação, ela ajudou muito”). }\end{array}$ \\
\hline $\begin{array}{l}\text { Pressões } \\
\text { miméticas }\end{array}$ & $\begin{array}{l}\text { - Resultam das incertezas de mercado, } \\
\text { levando muitas empresas a imitar ou } \\
\text { reproduzir os comportamentos utilizados } \\
\text { em outras organizações (DiMaggio \& } \\
\text { Powell, 1983); } \\
\text { - Resultam dos adotantes iniciais (Zucker, } \\
\text { 1987). }\end{array}$ & $\begin{array}{l}\text { - Empresas de consultoria, principalmente na adoção } \\
\text { inicial (E03: "a gente pegou uma empresa, que veio aqui } \\
\text { e fez uma avaliação do patrimônio"). }\end{array}$ \\
\hline
\end{tabular}

Fonte: elaborado pelos autores.

Em termos de pressões coercitivas, a legislação já havia sido identificada como o elemento que mais contribui nas decisões contábeis (Giner, 1997) para a adoção das IFRS (Doadrio et al., 2015) e para a divulgação dos relatórios contábeis (Touron, 2005; Jacomossi, Casagrande, \& Reis, 2015). Além disso, a adoção das IFRS no Brasil ocorreu em decorrência da Lei 11.638/2007 (Brasil, 2007), em conjunto com as orientações e pronunciamentos técnicos (50 no total) emitidos pelo CFC. Consequentemente, era esperada a forte influência desse elemento no JDM dos entrevistados.

A legislação, em alguns momentos, evidencia um caráter de persuasão e o contador a atende integralmente. Em outros, o contador decidiu não atendê-la, ou atendê-la de forma parcial, por duas 
razões principais: há outras forças coercitivas mais importantes (gestores, por exemplo) ou ele próprio não vislumbra benefícios com a adoção (racionalidade limitada). Além disso, os entrevistados não demonstraram receio em sofrer sanções por não atender as IFRS integralmente (nem por parte do CFC, nem por parte da Comissão de Valores Mobiliários (CVM) ou do mercado).

A influência dos gestores e da auditoria também é desigual. Em alguns momentos, se mostra impositiva, em outros, parece ser mais sutil, possivelmente porque, ao influenciarem as decisões relacionadas ao imobilizado, os gestores estão influenciando também o resultado da organização (muitas vezes atrelado a metas a serem atingidas). Já a auditoria tem caráter coercitivo em alguns momentos e normativo em outros. Por um lado, os contadores direcionam seu JDM no sentido de atender o que a auditoria determina. Por outro, os auditores também são contadores, com os quais os contadores das organizações trocam ideias e buscam soluções conjuntas. Por isso, muitas vezes os papéis coercitivo e normativo coexistem.

A influência de entidades regulamentadoras tem características próprias e merece destaque. Quando exercida pela CVM, contribui na adoção das IFRS, o que não ocorre no caso do Tribunal de Contas do Estado e da ANS (mesmo que ambos tenham poder de impor sanções pelo não cumprimento de normas próprias). Pela dificuldade em atender normatizações de diferentes origens, as IFRS acabam relegadas a um segundo plano. Essa influência não havia sido identificada em pesquisas anteriores. Essas pesquisas constataram que mercados financeiros (Albu et al., 2011), credores, autoridades fiscais (Zarzeski, 1996) e até organizações profissionais contábeis (Parboteeah et al., 2005) podem ter efeitos coercitivos na contabilidade.

A pressão normativa (professores, colegas de profissão) se manifesta pouco, também contrastando com achados anteriores (Doadrio et al., 2015). Esse resultado pode ser decorrente do período em que a maior parte dos entrevistados concluiu os estudos: antes da vigência das IFRS. Provavelmente os professores não abordaram o tema, por isso, não são considerados referência na área pelos entrevistados. O mesmo ocorre em relação aos colegas de profissão. As organizações dos entrevistados aderiram às IFRS em 2010, quando praticamente inexistiam organizações brasileiras que a adotaram, dificultando a busca por profissionais na área contábil considerados referência.

Para exercer a profissão, o contador deve estar vinculado ao conselho de classe e seguir suas recomendações. O CFC tem as funções principais de orientar, normatizar e fiscalizar o exercício da profissão contábil (Brasil, 1946). Sobre a função de orientação, os materiais publicados no site do Conselho de Regional de Contabilidade (CRC) do estado do Rio Grande do Sul (http://www.crcrs.org.br) mostram que os cursos e palestras disponibilizados não abordam as IFRS (das 250 palestras disponíveis, nenhuma está relacionada às IFRS). Nas ações de fiscalização, o foco recai sobre os escritórios de contabilidade (quase $80 \%$ do total). Essa pode ser uma explicação para a pouca influência do CRC observada no JDM dos contadores.

O isomorfismo mimético é caracterizado pela presença de empresas de consultoria no processo de adoção das IFRS, que pode ser considerada como uma de suas fontes (DiMaggio \& Powell, 1983; Christensen, 2003), porque tendem a aconselhar e implementar práticas semelhantes nas organizações em que atuam. Os resultados não permitiram evidenciar tal aspecto. A influência das empresas de consultoria foi considerada maior dentre os contadores que se declararam neutros e contrários à adoção das IFRS e menor dentre os favoráveis. Nesses casos, identifica-se o papel de legitimação da consultoria, pois parece que é ela quem direcionou o processo de adoção das IFRS em parte das empresas. Transcorrido esse período, o contador que não visualiza vantagens na norma mantém o que foi implementado pela consultoria, e tende a tomar parte das suas decisões de forma similar ao que fazia antes das IFRS.

\subsection{Análise integrada}

A Teoria da Racionalidade Limitada e a Teoria Institucional influenciaram o JDM dos contadores (ver Figura 1). Dado o contexto institucional da Contabilidade, com suas normas e regulamentos, foi proposta a P3: O JDM dos contadores é mais influenciado pelas pressões 
institucionais do que pelas limitações individuais no processo de controle do imobilizado. Observouse que essa influência não se manifesta da mesma forma em todos os tipos de decisões. Há momentos em que os elementos individuais predominam no JDM e outros em que os elementos institucionais são os mais importantes. Estudos sobre a influência conjunta das pressões institucionais e das limitações individuais sobre processos decisórios não foram encontrados na literatura, somente em separado. Por exemplo, Zucker (1987) e Scott (2008) apontaram que as pressões isomórficas se manifestam de diferentes formas e são percebidas diferentemente nas organizações. Chand et al. (2010) identificaram que as decisões relacionadas às IFRS são afetadas pela complexidade e pela familiaridade do contador com as normas. Os resultados encontrados nesta pesquisa detalham mais a influência desses elementos, mostrando que as decisões relacionadas a aspectos gerenciais de controle do imobilizado são mais influenciados pelas pressões coercitivas (características do ambiente). Já as limitações cognitivas, vinculadas ao contador, influenciam mais as decisões operacionais.

Figura 1 Como os elementos influenciam o JDM

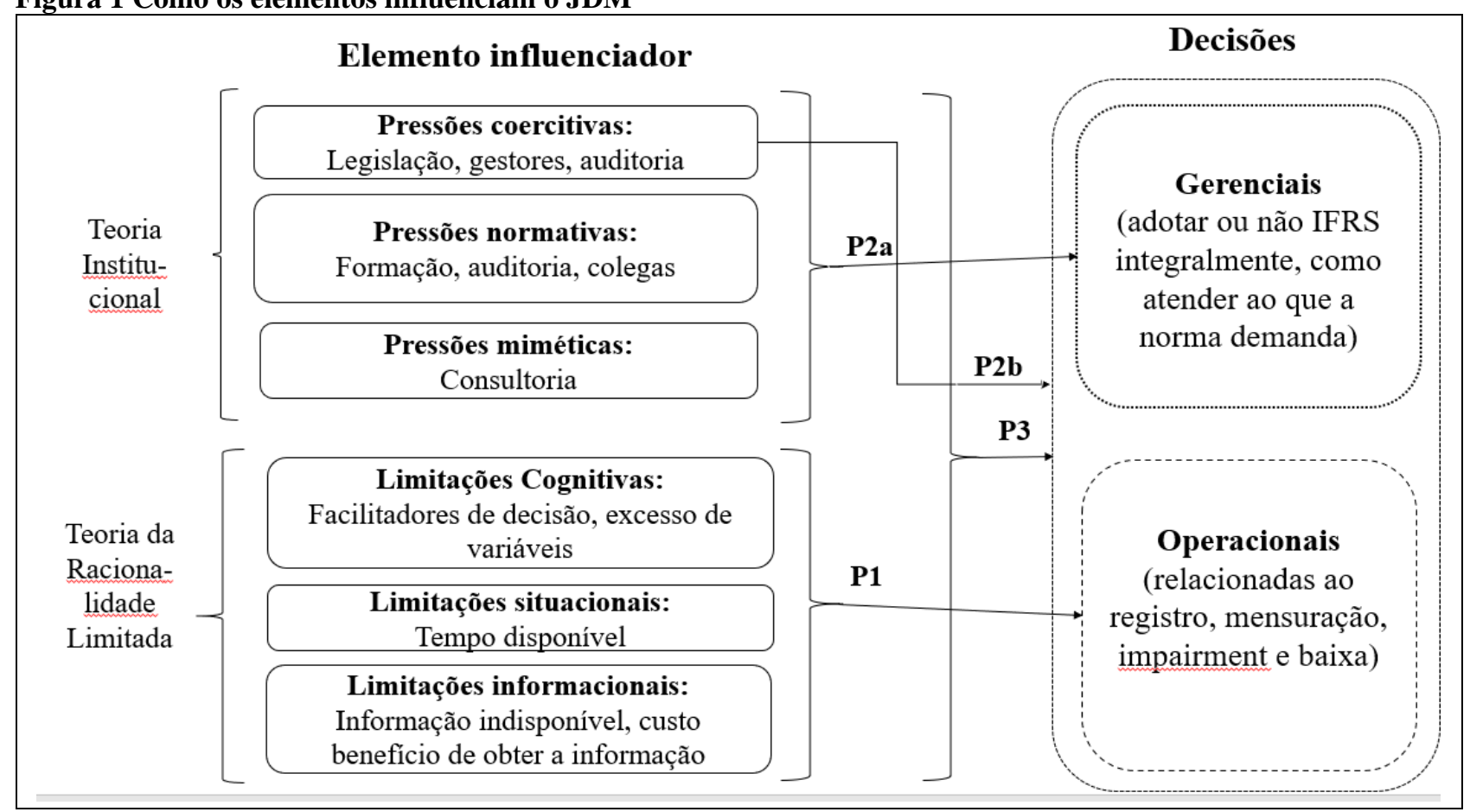

Fonte: Elaborada pelos autores.

As decisões operacionais demandam maior conhecimento técnico das IFRS, sendo necessárias à interpretação e implementação da norma. A vinculação estreita com a responsabilidade do contador, bem como o fato de que essas fazem parte do seu escopo de decisão podem motivar a maior influência das limitações individuais nesse tipo de decisões.

Já as decisões gerenciais relacionadas ao imobilizado envolvem aspectos que transcendem a contabilidade e que estão, de certa forma, além das atribuições do contador. A legislação, por exemplo, pode ser interpretada e permite alguma flexibilidade, mas não pode ser alterada ou totalmente ignorada pelo contador. Além disso, em última instância, a responsabilidade legal pela organização e pela publicação das demonstrações financeiras é dos detentores de capital e gestores. Logo, as decisões gerenciais em relação ao imobilizado envolvem aspectos mais amplos do que a contabilidade. Há indicativos de que esse contexto tenha contribuído para que as pressões coercitivas sejam mais intensas nesse tipo de decisão.

Para identificar o elemento mais relevante no contexto de cada decisão foi utilizada a Técnica dos Incidentes Críticos. Os eventos considerados críticos são aqueles em que foi possível associar pelo menos uma limitação individual e uma pressão ambiental a uma mesma tomada de decisão. Ao 
longo da pesquisa foram identificados 14 Incidentes Críticos, envolvendo as etapas do registro, cálculo da depreciação e teste de impairment. A título de exemplo, a Tabela 3 apresenta o Incidente Crítico no qual foi possível identificar a maior quantidade de elementos influenciando o JDM.

Tabela 3 - Incidente Crítico envolvendo teste de impairment

Contexto: o contador entende que não há a necessidade de realizar o teste de impairment anualmente, pois utiliza uma projeção de fluxo de caixa elaborado na adoção inicial.

\begin{tabular}{|c|c|}
\hline Elementos que influenciaram a decisão: & Pressão coercitiva (Gestores: diretoria) \\
\hline Pressão mimética (Consultoria) & Limitações situacionais (tempo) \\
\hline $\begin{array}{l}\text { Limitações cognitivas (Facilitador de decisão: pré- } \\
\text { classificações) }\end{array}$ & Limitações informacionais (Relação custo-benefício) \\
\hline
\end{tabular}

Trecho da transcrição:

P: Como é calculado o valor recuperável do ativo imobilizado?

E08: "não se faz o teste periodicamente. Isso também é uma coisa que foi feita pelo pelos especialistas, lá em 2010.

Eles fizeram uma projeção de fluxo de caixa descontado para 10 anos. Eu entendo, e também os proprietários da empresa, que esse cálculo ainda é válido."

P: Mesmo com a mudança na economia?

"Mesmo que a realidade tenha mudado um pouco com a crise. Foram feitos alguns ajustes no fluxo de caixa, e na prática, a empresa continua gerando resultado, continua dando lucro. Ninguém tem tempo sobrando, não se tem a preocupação de atualizar no detalhe o cálculo o tempo todo, não se vê vantagem em fazer isso.".

Fonte: elaborado pelos autores.

A análise conjunta dos elementos da Tabela 3 revela que o contador decide pela solução satisfatória de não realizar o teste anualmente. Por compartilhar da mesma opinião, a pressão dos proprietários da empresa dá ao contador tranquilidade em relação à decisão tomada, já que estes, que eventualmente poderiam forçar a adoção de um procedimento diferente, não o fazem. No incidente apresentado, a aceitação da solução satisfatória sugere que a limitação cognitiva (uso de facilitador de decisão) é o elemento que mais contribuiu para a decisão do contador. A análise global dos incidentes críticos também evidencia que as limitações cognitivas e as pressões coercitivas influenciam o JDM quase sempre de forma conjunta.

Porém, cada um dos incidentes envolve contadores e empresas diferentes. Logo, os elementos e o contexto no qual a decisão foi tomada também diferem. A predominância das limitações cognitivas não prevalece na pesquisa como um todo. Foi identificado que a pressão coercitiva (exercida em alguns momentos pela legislação, em outros pelos auditores, gestores ou detentores de capital) prevalece na maior parte das decisões. Na fala de E05 fica clara essa predominância: "Eles informam, mas a decisão mesmo vem da diretoria. Dada junto com os auditores. E gerência internacional né?".

O contexto legal em relação à adoção das IFRS é o mesmo para todos os contadores (e organizações). No entanto, as convicções e percepções individuais, a interpretação da legislação e o ambiente organizacional são distintos. Nesse contexto, é possível que cada contador tenha desenvolvido suas próprias estratégias de decisão, concebendo padrões baseados nas influências às quais está sujeito. Isso traz à tona a discussão das pressões coercitivas exercidas pelos gestores no JDM dos contadores. Nenhum dos entrevistados demonstrou desconforto em submeter suas decisões aos gestores. Pelo contrário, parece que eles consideram natural a influência desse grupo nas decisões relacionadas ao controle do imobilizado, poucas foram as situações envolvendo conflito entre os contadores e gestores.

Essa constatação leva ao questionamento do porquê isso ocorre. A influência dos gestores é majoritariamente relacionada a decisões que afetam o resultado. Há indícios de que as decisões dos contadores estão em consonância com esse objetivo, ou seja, eles também avaliam um possível impacto negativo no resultado em seu JDM. Durante as entrevistas, foi comum o uso de expressões como "a gente" e "nós", para caracterizar as organizações onde os contadores atuam, mostrando que há afinidade entre contador e organização. Disso se pode inferir que o contador, além de ser 
influenciado por limitações individuais e pressões ambientais, também direciona sua decisão no sentido de buscar o que considera ser a melhor alternativa para a organização.

As análises e discussões indicam que a contabilidade é elaborada sob as pressões do ambiente institucional em que o contador e a organização estão inseridos, mas que também apresenta características e segue o JDM do seu responsável legal, no caso, o contador. Com isso, a proposição P3 se confirma parcialmente, uma vez que a prevalência das pressões coercitivas não foi identificada em todas as etapas do JDM, nem em todos os tipos de decisões.

Foram identificadas situações em que a linha que separa a racionalidade limitada e as pressões institucionais é tênue. Por exemplo, quando um contador utiliza premissas fornecidas pela direção da empresa para elaborar o fluxo de caixa e, com base nesse fluxo de caixa, avalia se há indícios de perda por não recuperabilidade, está fazendo uso de um facilitador de decisão ou sofrendo uma pressão coercitiva? Uma análise com maior profundidade poderia fornecer maiores esclarecimentos: o contador tem liberdade de utilizar premissas diferentes? As premissas fornecidas pela direção correspondem à realidade e são exequíveis? Ou são excessivamente otimistas ou pessimistas?

Há também a dubiedade do papel da auditoria. Apesar da clara distinção conceitual entre os papéis normativo e coercitivo, esta se confunde no campo empírico. O contador, ao buscar uma solução para um problema em conjunto com o auditor, procura aconselhamento de um colega de profissão, que futuramente emitirá um parecer sobre a solução dada ao problema. Por participar da busca pela solução, é muito provável que o parecer dado pelo auditor seja favorável. Possivelmente o contador leva em consideração esse aspecto e a busca pela solução conjunta é um mecanismo utilizado por ele para aumentar a possibilidade de obter, futuramente, um parecer favorável por parte do auditor.

\section{CONSIDERAÇÕES FINAIS}

As IFRS impactam a profissão contábil, porque a mudança de uma contabilidade baseada em regras, para uma baseada em princípios aumenta o grau de julgamento exigido dos responsáveis pela elaboração das demonstrações (Ernst\&Young \& FIPECAFI, 2010). Nesse contexto, o objetivo do estudo de identificar os elementos que influenciam o JDM dos contadores no controle do imobilizado e como o fazem, baseados numa visão individual (de racionalidade limitada) e institucional, se reveste de importância.

Os resultados encontrados mostram que esse objetivo foi alcançado, pois evidenciaram que limitações cognitivas, situacionais e informacionais influenciam o JDM dos contadores (P1), com destaque para as limitações cognitivas - excesso de variáveis, uso de classificações prévias. Os resultados também revelaram que pressões coercitivas, normativas e miméticas influenciam o JDM dos contadores (P2a), com prevalência das pressões coercitivas - legislação, gestores, auditoria - e menor incidência das normativas e miméticas (P2b). Já a proposição P3, que foi parcialmente confirmada, mostra que decisões operacionais em relação ao controle do imobilizado são mais influenciadas pelas limitações individuais. Além disso, nas decisões relacionadas à gestão do imobilizado, as pressões institucionais são as mais influentes. A partir da Análise dos Incidentes Críticos, também é possível depreender que as pressões institucionais influenciam mais o JDM dos contadores nas situações em que normas e legislação são indissociáveis das atividades da contabilidade.

A realização do estudo sob a lente das duas teorias permitiu uma análise mais completa de um tema complexo, com três contribuições importantes a serem destacadas no campo teórico. A primeira, consiste na verificação de que tanto os elementos individuais quanto ambientais influenciam o JDM dos contadores, e que essa influência se dá em diferentes intensidades. Foi possível identificar situações em que as perspectivas individuais e ambientais influenciam conjuntamente o JDM, bem como em diferentes situações, uma se sobressai em relação a outra. Outra contribuição teórica diz respeito ao tipo de decisão que sofre maior influência de cada um dos elementos. Nas decisões de 
caráter operacional, as limitações individuais prevalecem. Nas decisões relacionadas à gestão do imobilizado, as mais influentes são as pressões coercitivas. A Figura 1 mostra as relações encontradas e representa uma importante contribuição, como proposição de framework para futuros estudos sobre JDM na área. Dentre esses, sugere-se utilizar a proposta de Lawrence, Suddaby, \& Leca (2011), para estudar, de forma detalhada, a relação entre as instituições e os atores, enfatizando a análise do porque as influências ocorrem.

No campo metodológico, a pesquisa mostrou a importância do uso do método qualitativo em estudos na área da contabilidade. Essa abordagem possibilitou a identificação de elementos influenciadores do JDM segundo a visão do responsável legal pela execução da contabilidade (o contador), auxiliando na compreensão de como ocorrem as decisões desses indivíduos, considerando elementos individuais e ambientais ou institucionais. A utilização da metodologia qualitativa possibilitou estudar em profundidade quais são elementos presentes no JDM e, principalmente, como eles afetam o JDM. A descrição da metodologia foi mais detalhada, com o propósito de mostrar ações tomadas para fomentar a validade dos resultados e a confiabilidade do processo investigativo. Apesar disso, a obtenção de informações a partir da percepção dos contadores e a não realização de um estudo longitudinal, com observações, pode ter influenciado os resultados obtidos e constitui uma limitação a ser evitada em estudos futuros. Outra limitação resulta do foco exclusivo no contexto decisório do controle do ativo imobilizado. Por isso, sugere-se aprofundar o estudo, adotando uma estratégia longitudinal, identificando o estágio e os componentes do processo de institucionalização, sob a perspectiva proposta por Tolbert e Zucker (1999). Também sugere-se estudar outros contextos decisórios do contador, ampliando, assim, a validade dos achados.

As contribuições para o campo profissional podem auxiliar os contadores a melhor compreender seu próprio JDM. Foi evidenciado que há limitações no processo decisório individual, que trazem benefícios e desvantagens. Ao mesmo tempo que essas limitações agilizam as decisões do contador, possibilitando a ele atender todas as demandas da contabilidade, elas o direcionam para aceitação de soluções satisfatórias em detrimento da ótima. Constatou-se, ainda, que pressões institucionais como a legislação são, de certa forma, indissociáveis da execução da contabilidade. Mas isso não significa que tenham o poder de determinar integralmente como a contabilidade é executada. Embora a análise em relação a como ocorre a influência dos elementos constatou a prevalência das pressões coercitivas, outras pressões institucionais e limitações individuais podem ter poder de influência superior ao da legislação, levando à adoção parcial das IFRS.

Independentemente das limitações individuais e das pressões institucionais às quais os contadores estão sujeitos como categoria profissional, parece que muitos ainda não conseguem visualizar os benefícios que as IFRS poderiam trazer para as organizações e para a própria contabilidade. A contabilidade elaborada em conformidade com as IFRS prioriza a essência sobre a forma e tem um potencial de gerar informações mais qualificadas. Com isso, o contador, ao invés de executar tarefas operacionais, poderia direcionar seus esforços para melhorar a informação contábil, aplicando seu JDM a questões mais relevantes. Como consequência, no longo prazo, a contabilidade deixaria de ser vista como uma obrigação fiscal (Cavalheiro, Huppes, \& Kremer, 2017), para ser considerada peça importante no gerenciamento das organizações. Para tanto, dada a carência, mencionada por alguns dos entrevistados, de materiais explicativos e de cursos ofertados por entidades reguladoras, instituições de ensino e empresas de treinamento, oportunidades de aperfeiçoamento em temas relacionados às IFRS deveriam ser incrementadas.

\section{REFERÊNCIAS}

Albu, N., Albu, C., Bunes, S., \& Calu, D. A. (2011) A story about IAS/IFRS implementation in Romania. Journal of Accounting in Emerging Economies, 1(1), 76-100.

Andrade, A. F., Fontoura, F. B., \& Macagnan, C. B. (2013). Um estudo sobre a evidenciação do ajuste a valor presente nas empresas listadas na BM\&FBovespa. Revista de Contabilidade do Mestrado em Ciências Contábeis da UERJ, 18(1), 62-80. 
Barbu, E. \& Piot, C. (2012). L'adoption des IAS/IFRS par les groupes français cotés. Revue française de gestion, 7, 53-74.

Binswanger, J. (2012). Life cycle saving: Insights from the perspective of bounded rationality. European Economic Review, 56(3), 605-623.

Bonner, S. E. (1999). Commentary: judgment and decision making research in accounting. Accounting Horizons, 13(4), 385-398.

Bonome, M. G. (2009). La racionalidad en la toma de decisiones: Análisis de la Teoría de la Decisión de Herbert A. Simón. La Coruña, ES: Netbiblo.

Brasil. (1946). Decreto-Lei $n^{\circ} 9.295$ de 27/05/1946 e alterações. Cria o Conselho Federal de Contabilidade, define as atribuições do Contador e do Guarda-livros e dá outras providências. Disponível em http://cfc.org.br/wp-content/uploads/2015/12/decretolei9295.pdf.

Brasil. (2007). Lei $n^{\circ} 11.638$, de 28/12/2007. Altera e revoga dispositivos da Lei no 6.404 e da Lei no 6.385, e estende às sociedades de grande porte disposições relativas à elaboração e divulgação de demonstrações financeiras. Disponível em: http://www.planalto.gov.br/ ccivil_03/ato20072010/2007/lei/111638.htm.

Callado, A. A. C. \& Pinho, M. A. B. (2015) Evidências de isomorfismo mimético sobre práticas de gestão de custos entre micro e pequenas empresas de diferentes setores de atividade. Contabilidade Vista \& Revista, 25(2), 119-137.

Carneiro, J., Rodrigues, L. L., \& Craig, R. (2017) Assessing international accounting harmonization in Latin America. In: Accounting Forum. Elsevier, 41(3), 172-184.

Carvalho, F. M., Lima, D. V., \& Ferreira, L. O. G. (2012). Processo de reconhecimento e mensuração do ativo imobilizado no setor público face aos padrões contábeis internacionais: um estudo de caso na Anatel. Revista Universo Contábil, 8(3), 62-81.

Cavalheiro, R. T., Huppes, C. M., \& Kremer, A. M. (2017) Aplicação das IFRS para pequenas e médias empresas na perspectiva dos prestadores de serviços contábeis. Revista Contabilidade e Controladoria, 9(2), 59-77.

Chand, P., Patel, C., \& Patel, A. (2010). Interpretation and application of "new" and "complex" international financial reporting standards in Fiji: Implications for convergence of accounting standards. Advances in Accounting, 26(2), 280-289.

Christensen, M. (2003) Without reinventing the wheel: business accounting applied to the public sector. Australian Accounting Review, 13(30), 22-27.

CFC. (2011). Resolução CFC N. ${ }^{o}$ 1.374/11. NBC TG Estrutura Conceitual - Estrutura Conceitual para Elaboração e Divulgação de Relatório Contábil-Financeiro. Disponível em: http://www2.cfc.org.br/sisweb/sre/ detalhes_sre.aspx?codigo=2011/001374.

CFC. (2017a). Resolução 2017/NBCTG27(R4). Altera a NBC TG 27 (R3) que dispõe sobre ativo imobilizado. Disponível em: https://www2.cfc.org.br/sisweb/sre/detalhes_sre.aspx? Codigo $=2017 /$ NBCTG27(R4)\&arquivo $=$ NBCTG27(R4).doc .

CFC. (2017b). Resolução 2017/NBCTG01(R4). Altera a NBC TG 01 (R3) que dispõe sobre redução ao valor recuperável de ativos. Disponível em: https://www2.cfc.org.br/sisweb/ sre/detalhes_sre.aspx?Codigo=2017/NBCTG01(R4)\&arquivo=NBCTG01(R4).doc.

CFC. (2019a). Norma Brasileira de Contabilidade, Nbc Pg 01, de 7 de Fevereiro de 2019. Aprova a NBC PG 01 - Código de Ética Profissional do Contador. Disponível em: https://www2.cfc.org.br/sisweb/sre/detalhes_sre.aspx?Codigo=2019/NBCPG01\&arquivo= NBCPG01.doc.

CFC. (2019b). Norma Brasileira de Contabilidade, NBC TG Estrutura Conceitual, de 21 de Novembro de 2019. Dá nova redação à NBC TG Estrutura Conceitual, que dispõe sobre a estrutura conceitual para relatório financeiro. Disponível em: https://www2.cfc.org.br/sisweb /sre/detalhes_sre.aspx?Codigo=2008/001121\&arquivo=Res_1121.doc.

Davis, G. B., Olson, M. H., \& Gama, A. P. (1987). Sistemas de información gerencial. New York: McGrawHill.

Delgado, L. \& Shealy, T. (2018). Opportunities for greater energy efficiency in government facilities by aligning decision structures with advances in behavioral science. Renewable and Sustainable Energy Reviews, 82(3), 3952-3961.

Dias Filho, J. M. \& Machado, L. H. B. (2012). Abordagens da pesquisa em contabilidade. In: Iudícibus, S. \& Lopes, A. B. Teoria Avançada da Contabilidade. 2. ed. S.P.: Atlas, 15-68. 
Dias, C., Lima Filho, R., Pinheiro, F., Silva, T., \& Moreira, R. (2014) Evidenciação de informações socioambientais, teoria da legitimidade e isomorfismo: um estudo com mineradoras brasileiras. Revista de Gestão e Contabilidade da UFPI, 1(1), 100-118.

DiMaggio, P. \& Powell, W. (1983). The iron cage revisited: institutional isomorphism and collective rationality in organizational field. American Sociological Review, 48(2), 147-160.

Doadrio, L.; Alvarado, M., \& Carrera, N. (2015). Reforma de la normativa contable española: análisis de su entramado institucional. Revista de Contabilidad, 18(2), 200-216.

Dufour, D.; Teller, P., \& Luu, P. (2015). A neo-institutionalist model of the diffusion of IFRS accounting standards. Computational Economics, 44(1), 27-44.

Eisenhardt, K. M. \& Zbaracki, M. J. (1992). Strategic decision making. Strategic Management Journal, 13(S2), 17-37.

Ernst \& Young \& FIPECAFI. (2010) Fundação Instituto de Pesquisas Contábeis, Atuariais e Financeiras. Manual de normas internacionais de contabilidade: IFRS versus normas brasileiras, v. 2, São Paulo: Atlas.

Flanagan, J. C. (1973) A técnica do incidente crítico. Arq. Bras. Psic. Apl., 25(2), 99-141.

Franco, R. (2009). The conjunction fallacy and interference effects. Journal of Mathematical Psychology, 53(5), 415-422.

Freire, M. D. M., Machado, M. R. R., Machado, L. S., Souza, E. S., \& Oliveira, J. J. (2012). Aderência às normas internacionais de contabilidade pelas empresas brasileiras, Revista de Contabilidade $e$ Organizações, 6(15), 3-22.

Hassan, M. C. (2008). The development of accounting regulations in Egypt. Managerial Auditing Journal, 23(5), 467-484.

Iudícibus, S., Martins, E., Gelbcke, E. R., \& Santos, A. (2018). Manual de contabilidade societária: aplicável a todas as sociedades de acordo com as normas internacionais e do CPC. 3 ed. São Paulo: Atlas.

Jacomussi, F. A., Casagrande, R. M., \& Reis, L. G. R. (2015). O isomorfismo nos relatórios de sustentabilidade: uma análise das empresas brasileiras que compõem o Dow Jones Sustainability Index. Revista de Gestão Ambiental e Sustentabilidade, 4(2), 49-64.

Kirk, J. \& Miller, M. L. (1986). Reliability and validity in qualitative research. Beverly Hills, CA: Sage.

KPMG (2011). Elevating professional judgment in auditing and accounting: The KPMG professional judgment framework. Disponível em: http://www.drlillie.com/a544/kpmg/jdgmt/KPMG_ProfJudgment_Monograph.pdf

Laitinen, E. K. \& Laitinen, T. (2015) A probability tree model of audit quality. European Journal of Operational Research, 243(2), 665-677.

Lawrence, T., Suddaby, R., \& Leca, B. (2011) Institutional work: Refocusing institutional studies of organization. Journal of Management Inquiry, 20(1), 52-58.

Lee, J., Keil, M., \& Wong, K. (2018). Does a tired mind help avoid a decision bias? The effect of ego depletion on escalation of commitment. Applied Psychology, 67(1), 171-185.

Lincoln, Y. \& Guba, E. (1985) Naturalistic Inquiry. Beverly Hills, CA: Sage.

Mala, R. \& Chand, P. (2014). Judgment and decision-making research in auditing and accounting: Future research implications of person, task, and environment perspective. Accounting Perspectives, 14(1), 150.

Messier, W. F., Quick, L. A., \& Vandervelde, S. D. (2014). The influence of process accountability and accounting standard type on auditor usage of a status quo heuristic. Accounting, Organizations and Society, 39(1), 59-74.

Meyer, J. W. \& Rowan, B. (1977) Institutionalized organizations: formal structure as myth and cerimony. American Journal of Sociology, 83(2), 340-363.

Nakane, P. M. \& Perez, G. (2014). A adoção da inovação definida pelas normas internacionais da contabilidade (IFRS) pelo profissional da área contábil no Brasil. Revista Jovens Pesquisadores Makenzie, 11(2).

North, D. C. (1990). Institutions, institutional change and economic performance. New York, Cambridge University Press.

Parboteeah, K. P., Cullen, J. B., Victor, B., \& Sakano, T. (2005). National culture and ethical climates: A comparison of U.S. and Japanese accounting firms. Management International Review, 45(4), 459480 . 
Paulus, T. M., Woods, M., Atkins, D. P., \& Macklin, R. (2017). The discourse of QDAS: Reporting practices of ATLAS. ti and NVivo users with implications for best practices. International Journal of Social Research Methodology, 20(1), 35-47.

Perez, M. M. \& Famá, R. (2006). Ativos intangíveis e o desempenho empresarial, Revista Contabilidade \& Finanças, 17(40), 7-24.

Politelo, L., Kaveski, I. D. S., \& Klann, R. C. (2014). Evidenciação do valor justo de ativos financeiros das empresas listadas na BM\&FBovespa. Desenvolvimento em Questão, 12(28), 318-347.

Qi, Y. (2014). Intervention and display of accounting professional judgment via performance. Third International Conference on Science and Social Research (ICSSR 2014). Atlantis Press.

Rezende, A. J., Guerreiro, R., \& Dalmacio, F. Z. (2012). An analysis of the deinstitutionalization of inflation-adjusted accounting practices in Brazilian companies. Revista Contabilidade \& Finanças, 23(58), 33-51.

Rodrigues, L. L. \& Craig, R. (2007). Assessing international accounting harmonization using Hegelian dialectic, isomorphism and Foucault. Critical Perspectives on Accounting, 18(6), 739-757.

Ross, D. (2014) Psychological versus economic models of bounded rationality. Journal of Economic Methodology, 21(4), 411-427.

Saldaña, J. (2009). The coding manual for qualitative researchers. L.A.: Sage, 2009.

Sbicca, A. (2014). Heurísticas no estudo das decisões econômicas: Contribuições de Herbert Simon, Daniel Kahneman e Amos Tversky. Estudos Econômicos, 44(3), 579-603.

Scapens, R. W. (1994). Never mind the gap: towards an institutional perspective on management accounting practice. Management Accounting Research, 5, 301-321.

Scott, W. R. (2008). Institutions and organizations: Ideas and interests. L. A.: Sage.

Silva, A. A. \& Naldis, V. B. (2012) Incerteza e racionalidade limitada: Um estudo empírico no setor financeiro. Revista Organizações em Contexto-online, 8(15), 43-63.

Silva, J. S., Silva, A. H. C., \& Laurencel, L. C. (2016). Nível de evidenciação obrigatória nas empresas de capital aberto: uma análise do CPC 27. Pensar Contábil, 18(65), 40-50.

Simon, H. A. (1955) A behavioral model of rational choice. Quarterly Journal of Economics, 69, 99-118.

Simon, H. A. (1965). Comportamento administrativo, estudo dos processos decisórios nas organizações administrativas. 2 ed. Rio de Janeiro: Fund. Getúlio Vargas.

Smith, V. L. (2005). Behavioral economics research and the foundations of economics. The Journal of Socio-Economics, 34(2), 135-150.

Tolbert, P. \& Zucker, L. G. (1999). The institutionalization of institutional theory. In: Clegg, S. \& Hardy, C. Handbook of Organization Studies, v1. London: Sage, 169-184.

Touron, P. (2005). The adoption of US GAAP by French firms before the creation of the International Accounting Standard Committee: an institutional explanation. Critical Perspectives on Accounting, $16(6),, 851-873$.

Trotman, K. T., Tan, H. C., \& Ang, N. (2011). Fifty-year overview of judgment and decision-making research in accounting. Accounting \& Finance, 51(1), 278-360.

Tuttle, B. \& Dillard, J. (2007). Beyond competition: Institutional isomorphism in US accounting research. Accounting Horizons, 21(4), 387-409.

Tversky, A. \& Kahneman, D. (1974). Judgment under uncertainty: Heuristics and biases. Science, 185(4157), 1124-1131.

Zarzeski, M. T. (1996). Spontaneous harmonization effects of culture and market forces on accounting disclosure practices. Accounting horizons, 10(1), 18.

Zorn, T. E.; Flanagin, A. J., \& Shoham, M. D. (2011). Institutional and non-institutional influences on information and communication technology adoption and use among nonprofit organizations. Human Communication Research, 37(1), 1-33.

Zucker, L. G. (1987) Institutional theories of organization. Annual Review of Sociology, 13(1), 443-464. 


\section{APÊNDICE A: ROTEIRO DE ENTREVISTAS}

\begin{tabular}{|c|c|}
\hline Questões & Fundamentação \\
\hline $\begin{array}{l}\text { Quais são os critérios utilizados para } \\
\text { definir se um item deve ser registrado } \\
\text { no imobilizado? }\end{array}$ & $\begin{array}{l}\text { Limitações cognitivas individuais (facilitador de decisão: critério fiscal, } \\
\text { pré-classificações) (Bonoma, 2009; Davis, Olson, \& Gama, 1987) } \\
\text { Pressões coercitivas (gestores, auditoria) (Freitas \& Guimarães, 2007) } \\
\text { CPC 27, itens } 7 \text { e } 8 \text {. }\end{array}$ \\
\hline $\begin{array}{l}\text { Os itens do imobilizado são registrados } \\
\text { individualmente ou por unidade } \\
\text { geradora de caixa? (conta contábil } \\
\text { individual, itens de pequeno valor são } \\
\text { agrupados, diferença entre itens de } \\
\text { pequeno e grande valor) }\end{array}$ & $\begin{array}{l}\text { Limitações cognitivas individuais (facilitador de decisão: critério fiscal, } \\
\text { pré-classificações) (Bonoma, 2009; Davis, Olson, \& Gama, 1987) } \\
\text { Limitação informacional (custos, benefícios) (Simon, 1965; Sbicca, } \\
2014 \text { ) } \\
\text { CPC } 27 \text {, itens } 9 \text { e } 10 .\end{array}$ \\
\hline $\begin{array}{l}\text { O que é levando em consideração para } \\
\text { determinar o valor pelo qual o item é } \\
\text { registrado no imobilizado? (custos } \\
\text { atribuíveis como fretes, adequação do } \\
\text { prédio, desmontagem) }\end{array}$ & $\begin{array}{l}\text { Limitações cognitivas individuais (facilitador de decisão: critério fiscal, } \\
\text { pré-classificações) (Bonoma, 2009; Davis, Olson, \& Gama, 1987) } \\
\text { Limitação informacional (custos, benefícios) (Simon, 1965; Sbicca, } \\
2014 \text { ) } \\
\text { CPC } 27 \text {, itens } 15 \text { a } 28 \text {. }\end{array}$ \\
\hline $\begin{array}{l}\text { Como é calculada a depreciação? (vida } \\
\text { útil, valor residual, quotas constantes, } \\
\text { quantidade produzida) }\end{array}$ & $\begin{array}{l}\text { Limitações cognitivas individuais (facilitador de decisão: critério fiscal, } \\
\text { pré-classificações) (Bonoma, 2009; Davis, Olson, \& Gama, 1987) } \\
\text { Limitação informacional (custos, benefícios) (Simon, 1965; Sbicca, } \\
2014 \text { ) } \\
\text { Pressão normativa (auditoria) (Touron, 2005) } \\
\text { CPC 27, itens } 43 \text { a 62. }\end{array}$ \\
\hline $\begin{array}{l}\text { Houve alterações nos critérios e formas } \\
\text { de registro do imobilizado após a } \\
\text { IFRS? Quais? (como foi a mensuração } \\
\text { inicial) }\end{array}$ & $\begin{array}{l}\text { Limitações cognitivas individuais (facilitador de decisão: pré- } \\
\text { classificações) (Bonoma, 2009; Davis, Olson, \& Gama, 1987) } \\
\text { Limitações situacionais (tempo limitado) (Sbicca, 2014) } \\
\text { Pressão coercitiva (legislação, auditoria) (Freitas \& Guimarães, 2007; } \\
\text { Touron, 2005)) } \\
\text { Pressão mimética (consultoria) (DiMaggio \& Powell, 1983) }\end{array}$ \\
\hline $\begin{array}{l}\text { Como é calculado o valor recuperável } \\
\text { do ativo imobilizado? (fluxo de caixa } \\
\text { descontado, previsão das vendas, } \\
\text { inflação, quem faz? Com que } \\
\text { periodicidade?) }\end{array}$ & $\begin{array}{l}\text { Limitações cognitivas individuais (facilitador de decisão: pré- } \\
\text { classificações) (Bonoma, 2009; Davis, Olson, \& Gama, 1987) } \\
\text { Pressão coercitiva (legislação, gestores) (Freitas \& Guimarães, 2007) } \\
\text { Limitações situacionais (tempo limitado) (Sbicca, 2014) } \\
\text { Pressão mimética (consultoria) (DiMaggio \& Powell, 1983) } \\
\text { CPC 27, item } 63 \\
\text { CPC 01, itens } 30 \text { a } 57\end{array}$ \\
\hline $\begin{array}{l}\text { Já houve alguma perda por impairment? } \\
\text { Se sim, qual foi o tratamento dado a esta } \\
\text { perda? }\end{array}$ & $\begin{array}{l}\text { Pressão coercitiva (entidades regulamentadoras, gestores, auditoria) } \\
\text { (Freitas \& Guimarães, 2007, Touron, 2005) } \\
\text { Pressão mimética (consultoria, outros contadores) (DiMaggio \& Powell, } \\
1983 \text { Zucker, 1987) } \\
\text { CPC 01, itens 58 a 64. }\end{array}$ \\
\hline $\begin{array}{l}\text { Como é o levantamento e identificação } \\
\text { das informações e variáveis necessárias } \\
\text { à realização dos cálculos citados nas } \\
\text { questões anteriores? (outras pessoas as } \\
\text { fornecem, disponibilidade, } \\
\text { confiabilidade) }\end{array}$ & $\begin{array}{l}\text { Limitações cognitivas individuais (facilitador de decisão: pré- } \\
\text { classificações) (Bonoma, 2009; Davis, Olson, \& Gama, 1987) } \\
\text { Pressão coercitiva (legislação, gestores) (Freitas \& Guimarães, 2007) } \\
\text { Limitações situacionais (tempo limitado) (Sbicca, 2014) } \\
\text { CPC 01, itens } 7 \text { a 64. }\end{array}$ \\
\hline $\begin{array}{l}\text { Em algum momento, a opinião ou } \\
\text { recomendação de terceiros teve } \\
\text { influência no registro e mensuração } \\
\text { ativo imobilizado? (considerar também } \\
\text { a adoção inicial) }\end{array}$ & $\begin{array}{l}\text { Pressão coercitiva (entidades regulamentadoras, gestores, auditoria) } \\
\text { (Freitas \& Guimarães, 2007, Touron, 2005) } \\
\text { Pressão mimética (consultoria, outros contadores) (DiMaggio \& Powell, } \\
1983 \text { Zucker, 1987) }\end{array}$ \\
\hline $\begin{array}{l}\text { Você considera que sua formação } \\
\text { formal (graduação e outros cursos) tem } \\
\text { influência na forma de mensuração do } \\
\text { imobilizado e interpretação das IFRS? }\end{array}$ & $\begin{array}{l}\text { Limitações cognitivas individuais (complexidade, conhecimento) } \\
\text { (Chand, Patel, \& Patel, 2010) } \\
\text { Pressão normativa (Di Maggio \& Powell, 1983; Touron, 2005; } \\
\text { Parboteeah et al., 2005) }\end{array}$ \\
\hline $\begin{array}{l}\text { Caso houvesse discordância importante } \\
\text { em relação ao imobilizado (registro, }\end{array}$ & $\begin{array}{l}\text { Limitações cognitivas individuais (complexidade, conhecimento) } \\
\text { (Chand, Patel, \& Patel, 2010) }\end{array}$ \\
\hline
\end{tabular}




\begin{tabular}{|l|l|}
$\begin{array}{l}\text { mensuração ou reconhecimento de } \\
\text { perda), na sua opinião, a posição de } \\
\text { quem prevaleceria? }\end{array}$ & $\begin{array}{l}\text { Pressão coercitiva (entidades regulamentadoras, gestores, auditoria) } \\
\text { (Freitas \& Guimarães, 2007, Touron, 2005) }\end{array}$ \\
\hline $\begin{array}{l}\text { Como ocorre a baixa dos itens do } \\
\text { imobilizado? (somente pela venda, se } \\
\text { não é mais utilizado, há reclassificação } \\
\text { para venda) }\end{array}$ & $\begin{array}{l}\text { Limitações cognitivas individuais (facilitador de decisão: pré- } \\
\text { classificações) (Bonoma, 2009; Davis, Olson, \& Gama, 1987) } \\
\text { Pressão coercitiva (legislação, gestores) (Freitas \& Guimarães, 2007) } \\
\text { Limitações situacionais (tempo limitado) (Sbicca, 2014) } \\
\text { CPC 27, itens 67 a 72 }\end{array}$ \\
\hline $\begin{array}{l}\text { Há alguma outra informação que você } \\
\text { julga importante, sobre a qual não } \\
\text { conversamos? }\end{array}$ & $\begin{array}{l}\text { Questão aberta para coletar outras informações que o entrevistado deseja } \\
\text { fornecer (controle do ativo imobilizado, adoção das IFRS, etc.). }\end{array}$ \\
\hline
\end{tabular}

